\title{
Evaluation of Color Sticky Cards for Monitoring Aphid Population on Okra Crop
}

\author{
Tufail Ahmed Wagan* Ghulam Murtaza Nusrat Hussain Abbasi \\ Abdul Samee Asif Ali Asadullah \\ Department of Plant Protection Shaheed Zulfiqar Ali Bhutto Agricultural College, Dokri, Pakistan
}

\begin{abstract}
Okra is the most familiar and widely known for its edible fruits. Several sucking and chewing insect species infest okra crop in the field. The field study was conducted to determine the attraction of four different colored traps to aphids in okra field. It is hoped that the information from this study will be able to help in the monitoring and management of these pests, as well as enhance integrated pest management programs in Pakistan and other countries with similar ecological conditions. The okra seeds were sown on both sides of well-prepared ridges. Red, blue, green and white colored sheets of sticky paper placed in the field with the help of bamboo stakes. The aphids were counted on sticky cards after 24 hours of their application. Aphid population appeared on okra from first week of observation and remained until last observation. Red colored attract maximum number of aphids, followed by green, white and blue. Plant vegetative and reproductive growth increased regularly with increase of crop age.
\end{abstract}

DOI: $10.7176 /$ ALST/74-02

Publication date:May $31^{\text {st }} 2019$

\section{Introduction}

Okra, Abelmoschus esculentus L. (Moench) is among the most familiar and widely known species of the family Malvaceae (Naveed et al., 2009). It is annual vegetable reaped in summer, and thought to be native to Africa, South East Asia and North Australia in the Pacific (Pandita et al., 2010). Okra is valued for its edible fruits; its fruit contains many seeds inside that can be consumed as a fried or boiled vegetable or may be added to soups, salads and stews (Kashif et al., 2008). Pests are one of the serious challenges facing crop production today. Bemisia tabaci, Thrips tabaci, Amrasca devastans, Aphis gossypii, Earias spp and Helicoverpa armigera are considered as most destructive insect species, which attacking crop from sowing till the harvest (Shabozoi et al. 2011, Sahito et al., 2012, Aziz, 2012). Although there are many ways to insect infestation, but normally such pests are controlled by hazardous chemicals, which, when released into the environment, can have a negative global impact. Such concerns have created a need for analogous controls designed with safety in mind.

Colored sticky-traps are a low-cost and simple method for monitoring and controlling the insect species on many crops (Lessio and Alma, 2004; Raja and Arivudainambi, 2004). For instance, different colored cylindrical sticky traps placed at a height of 157.5 are an effective means of controlling aphids (Disney et al., 1982). Keeping that in mind, a simple, cheap and easily managed method for control of insect species was introduced. A field trial was conducted to determine the attraction of four different colored traps to aphids in okra field. It is hoped that the information from this study will be able to help in the monitoring and management of these pests, as well as enhance integrated pest management programs in Pakistan and other countries with similar ecological conditions.

\section{Material and Methods \\ Experiment}

The field study was carried out at Shaheed Zulfiqar Ali Bhutto Agricultural College Dokri situated at $27.3743^{\circ}$ (N) North latitude, $68.0967^{\circ}$ (E) East longitude and has an altitude of 131 feet. During the spring and early summer season (February to May) to evaluate the attractive effects of different colors on insect pests. The okra seeds cultivated were the Rama Krishna variety, the distance between rows was $40-45 \mathrm{cms}$ and from plant to plant, $8-10 \mathrm{cms}$. Seeds were sown on $15^{\text {th }}$ of February on both sides of well-prepared ridges. Four different red, blue, green and white colors in human eyes were used to trap adult aphids. After 25 days of germination, colored sheets of sticky paper $(20 \times 20 \mathrm{~cm})$ placed at randomly in the field with the help of bamboo stakes. The cards placed at $30 \mathrm{cms}$ above the plants with 5 meters distance between cards. No pesticides were used for pest management throughout the research period. Irrigation and weeding were done whenever was needed.

Field studies and data analysis

Sticky cards were placed in the field in morning (9am to $10 \mathrm{am}$ ) and replaced after 24 hours. The traps were examined under microscope and adult aphids were counted and recorded from each coloured sticky card. The activity was repeated every five day and a total of 12 collections were recorded of each color. Microsoft office excel 2007 was used to analyses data and draw figures. 


\section{Result}

The population of aphid on the Sticky traps

All color used in our experiment were aphid attractant. Red colored attract maximum number of aphids, followed by green, white and blue. Aphid population appeared on okra from first week of observation and remained until last observation (Fig. 1). Maximum numbers of aphids were trapped by red color card. The minimum aphid population on red sticky card was recorded in the first observation with mean number of 12.87 per sticky card, while the maximum aphid population was recorded in the eighth observation with mean number 24.06 per card (Fig. 1). After red colored sticky trap, the green sticky trap was the second attractant for aphids; the maximum aphid population (77.58 per sticky card) was collected from the eight week of observation, while the minimum population (11.11 per sticky card) was observed in the first week of recording (Fig. 1). For aphid attraction, the white color was on thirds number, the minimum aphid population (4.25 per sticky card) was observed in the first week and maximum population (68.03 per sticky card) was observed on eight week (Fig. 1). In our experiment blue color sticky trap was the lowest in aphid attraction as compared to other colors. The minimum number of aphids (4.60 per sticky card) was observed on first observation, while the maximum number of aphids (44.31 per sticky card) was observed on eight time of observation (Fig. 1).

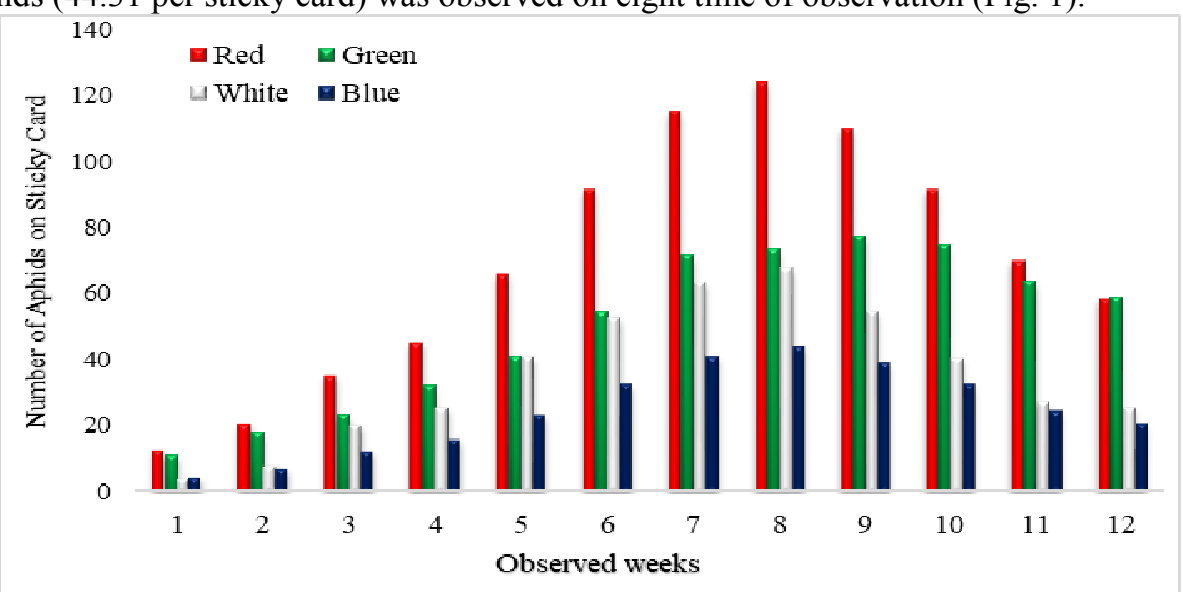

Fig. 1. Population of aphids on different colored sticky traps, values are mean of 10 replications.

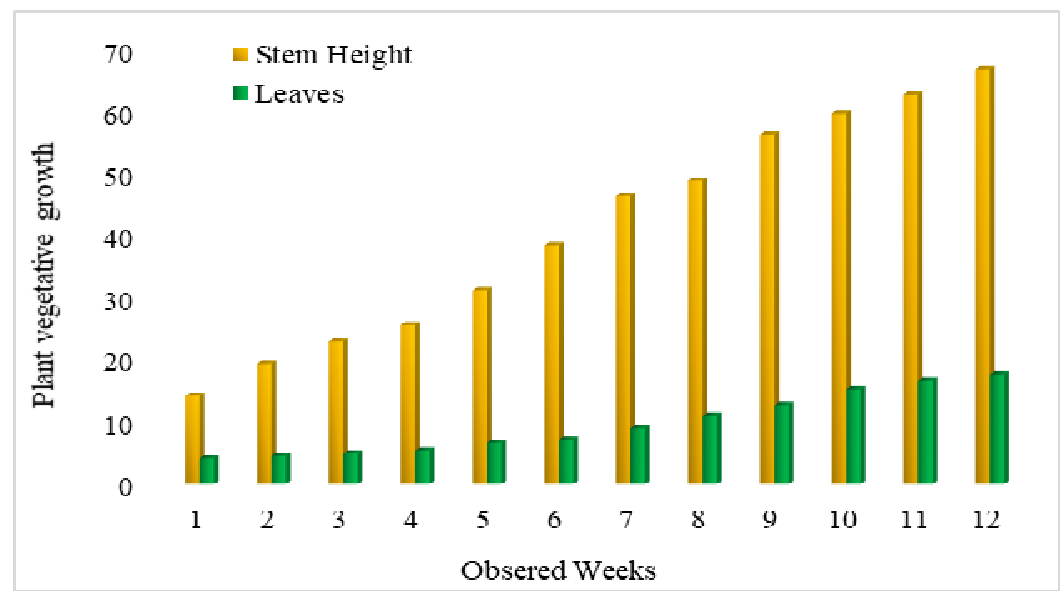

Fig. 2. Vegetative growths of okra crop, values are the mean of 10 replications

Plant vegetative and reproductive growth

The results of our study showed that plant vegetative and reproductive growth increased regularly with increase of crop age. The maximum numbers of leaves 17.60 per plant were recorded in the last observation. The maximum plant height $66.70 \mathrm{~cm}$ was recorded in the last recording (Fig. 2). Plant bear square after the third week of observation. The maximum number of squares (5.90 per plant) was recorded in the ninth observation. The maximum numbers of flowers $\left(5.6\right.$ per plant) were recorded in the $10^{\text {th }}$ observation, and the maximum numbers of fruits (3.60 per plant) were recorded in the last observation (Fig. 3). 


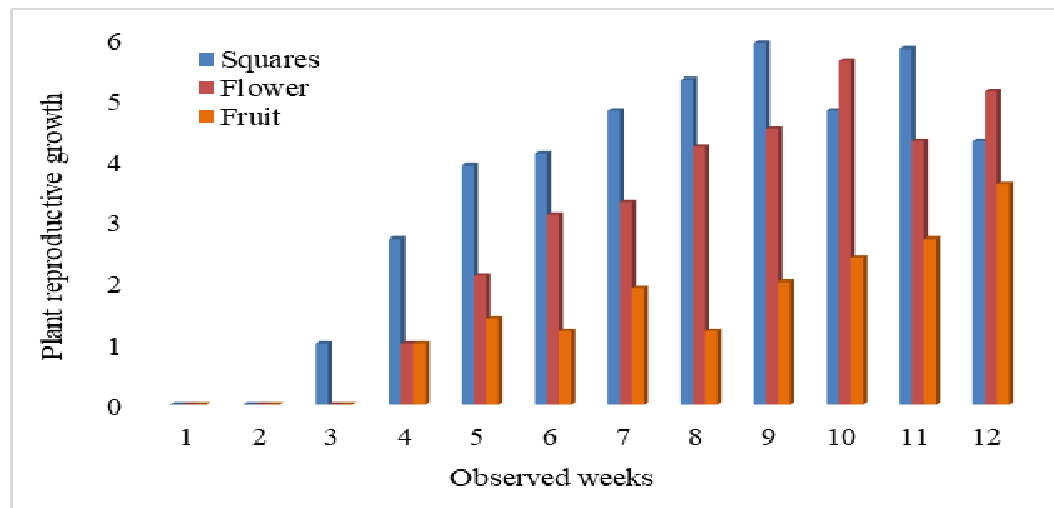

Fig. 3. Reproductive growths of okra crop, values are the mean of 10 replications

\section{Discussion}

Our study showed that the aphids were attracted by all colors, different colors showed different population percentages. Related results of color attraction to insect species were also reported by Prokopy \& Owens (1983), who found that insect species have positive responses to the colors. The use of Green, purple, yellow, and black colored sticky traps shows good results for monitoring and managing okra's insect pests in subtropical climate conditions. Green, purple, yellow, and black sticky traps can attract whitefly and thrips population in okra crop (Wagan et al. 2017). Most insects attract if the colored cards are at a height of $70 \mathrm{~cm}$ or above (Gharekhani, et al. 2014). The crop vegetative and reproductive growth was normal and frequently increased with increased of time during our study. It has been proved that if the insect pest population is under control then plants become healthy and give maximum growth and production.

\section{Conclusions}

The use of colored sticky traps shows good results controlling and monitoring Aphids. Red is the most attractive color to aphids, followed by green, white and blue. Furthermore, this study concluded that using different colored traps for okra crop protection was significantly less expensive and less hazardous than chemical insecticides.

\section{Reference}

1. Naveed, A., Khan A. A., \& Khan. I.A. (2009). Generation mean analysis of water stress tolerance in okra (Abelmoschus esculentus L.). Pakistan Journal of Botany, 41, 195-205.

2. Wagan, T. A., Dhaunroo, A. A., Jiskani, W. M., Sahito, M. H., Soomro, A. A., Lakho, A. B. J., Wagan, S. A., Memon, Q. A., \& Tunio, S. K. (2017). Evaluation of four color sticky traps for monitoring whitefly and thrips on okra crops at Tando Jam, Pakistan. Journal of Biology, Agriculture and Healthcare, 7, 12-15.

3. Gharekhani, G. H., Ghorbansyahi, S., Saber, M., \& Bagheri, M. (2014). Influence of the color and height of sticky traps in attraction of thrips tabaci (Lindeman) (Thysanoptera, Thripidae) and predatory thrips of family Aeolothripidae on garlic, onion and tomato crops. Phytopathol Plant Protection, 47, 18

4. Lessio, F., Alma A. (2004). Dispersal patterns and chromatic response of Scaphoideus titanus Ball (Homoptera: Cicadellidae) vector of the phytoplasma agent of grapevine Flavescence dorée. Agriculture and Forest Entomology, 6, 121-127.

5. Prokopy, R. J., \& Owens, E. D. (1983). Visual Detection of Plants by Herbivorous insects. Annuals Review of Entomology, 28, 337-364

6. Raja, K. M. \& Arivudainambi, S. (2004). Efficacy of sticky traps against bhendi leaf hopper, Amrasca biguttula biguttula Ishida. Insect Environment, 10, 32-32.

7. Shabozoi, N. U. K., Abro, G. H., Syed, T. S., Awan, M. S. (2011). Economic appraisal of pest management options in Okra. Pakistan Journal of Zoology, 43, 869-878

8. Sahito, H. A., Abro, G. H., Memon, S. A., Mal, B., \& Mahmood, R. (2012). Influence of abiotic factors on population development of Bemisia tabaci infesting Abelmoschus esculentus. International Research Journal of Plant Science, 3, 12-18

9. Aziz, M. A. (2012). Roll of different physio-chemical characters of okra as a host plant for preference of Earias spp. Pakistan Journal of Zoology, 44, 361-369.

10. Padita, V. K., Anand, A., Nagarajan, S., Seth, R. \& Sinha, S. N. (2010). Solid matrix priming improves seed emergence and crop performance in okra. .

11. Kashif, S.R., Yaseen, M., Arshad, M. \& Ayub, M. (2008). Response of okra (Hibiscus esculentus L.) to soil given encapsulated calcium carbide. Pakistan Journal of Botany, 40, 175-181. 